Stefanie Werner and Wolfgang Meier, Measurement of evaporation of hydrocarbon droplets by laser absorption spectroscopy, Applied Physics B 126 (2019) 13.

The original publication is available at www.springerlink.com

http://dx.doi.org/10.1007/s00340-019-7363-0 


\title{
Measurement of evaporation of hydrocarbon droplets by laser absorption
}

\section{spectroscopy}

\author{
Stefanie Werner ${ }^{1}$ and Wolfgang Meier ${ }^{1}$ \\ German Aerospace Center (DLR), Institute of Combustion Technology, Pfaffenwaldring 38-40, 70565 Stuttgart, Germany
}

Received: date / Revised version: date

\begin{abstract}
Concentration measurements of evaporated hydrocarbon species by infrared laser absorption spectroscopy at a monodisperse droplet chain are presented. A droplet generator was installed within a flow channel and operated with cyclohexane, iso-octane, $n$-heptane, $n$-pentane and 1-butanol. The flow channel was flushed with a laminar flow of air at different temperatures. The absorption of a HeNe laser beam at $\lambda=3.39 \mu \mathrm{m}$ traversing through the flow channel at varying distances from the droplet chain was exploited to determine the vapor concentrations of the hydrocarbons. Measurements of the absorption cross sections in a heated gas cell $(\mathrm{T}=$ frequency and droplet spacing. In the investigated temperature range of the air $(313-430 \mathrm{~K})$ the evaporation rates increased linearly with temperature. The order of the fuels with respect to evaporation rates corresponded with the boiling points of the individual fuels. In addition to the presentation of the results, the paper discusses the performance of vapor concentration measurements by laser absorption spectroscopy at droplet chains which has not been tested before in such a configuration. Particular attention was paid to the spatial resolution of the measurement. The results are well suited to validate models and numerical simulations.
\end{abstract} 300 to $773 \mathrm{~K}$ ) enabled the quantification of the absorption signals from the droplet chain. Vapor concentrations were determined in planes perpendicular to the droplet chain. From the increase of vapor concentration between the planes, the evaporation rate could be determined. The evaporation rates were measured in dependence of co-flow temperature, droplet velocity, droplet generation

\section{Introduction}

The physical and chemical processes in spray flames involve the atomization of the liquid fuel, the dispersion and evaporation of the filaments and droplets, the mixing of fuel vapor and oxidizer and the chemical reactions. 
Each of these processes is in itself a very demanding subject and their interaction represents a highly complex process. The complexity is even increased if a turbulent flow field and technical fuels like diesel, heating oil or kerosene are considered. An essential goal of combustion research is the development of numerical methods for reliably calculating spray combustion and designing technical combustion chambers. The verification and improvement of the methods is essentially based on the availability of experimental results from experiments with well-defined boundary conditions. This concerns both the individual sub-processes and their interaction in complex configurations. The sub-process considered in this publication is evaporation of fuel droplets.

Extensive research work has been performed to model and simulate spray evaporation [1-5]. However, there is still a lack of understanding, particularly for multicomponent fuels, droplet-droplet interaction and the interaction of droplets with a turbulent reacting flow field. Similar effort has been made in the experimental investigations of spray evaporation. Suspended droplets and monodisperse droplet chains represent a configuration with well-defined boundary conditions that have often been used for basic investigations [6-10]. These configurations enable highly reproducible measurements and are ideally suited for the application of a large variety of measurement techniques, particularly optical and laserbased techniques $[11,12]$. A standard method to measure the droplet size and refractive index is rainbow refrac- tometry [13-15] which has been applied for monodisperse droplet chains as well as for sprays. The change in droplet size can be directly linked to the evaporation rate. There are several other techniques for the determination of the droplet diameter. A relatively simple method is shadowgraphy [16]. Phase Doppler Anemometry is widely applied to determine the droplet size and velocity distribution simultaneously, often in combination with other techniques such as rainbow refractometry $[17,18]$. Several laser methods are based on laser-induced fluorescence (LIF) for the determination of species concentrations and temperature in the liquid or gaseous phase. Examples for the extensive investigations with these methods can be found in the review articles of Lemoine and Castanet [11] and Fansler [19]. Other techniques such as Raman scattering, thermographic phosphors or molecular tagging velocimetry are also addressed in those articles.

With respect to the studies presented here, concentration measurements of vaporized fuel in the vicinity of droplets are of particular interest. In principle, laser Raman scattering is suitable [20] because its signal intensity is proportional to the species number density. It is to a certain extent species selective and the signal processing is not complicated by quenching or other effects stemming from molecular collisions [21,22]. However, the scattering cross section is extremely small so that high power lasers and efficient detection optics are needed. Further, the Raman scattering signal may be affected by 
interferences from Mie scattering or laser-induced fluorescence.

The spatial resolution of the measurements is an important aspect for all measurement techniques when concentration profiles in the immediate vicinity of droplet are to be determined. In a monodisperse droplet chain, the droplet diameters are on the order of $100 \mu \mathrm{m}$ and concentration gradients close to the droplet surface are large. Thus, a spatial resolution of better than $100 \mu \mathrm{m}$ is needed to resolve the spatial structures. This presents a challenge, not only for laser Raman scattering.

For concentration measurements in the gas phase, LIF is a widely applied method. Important fuel components such as alkanes can hardly be excited to LIF in air because their absorption bands lie in the vacuum ultraviolet range. For such fuels various tracers have been analyzed and used which are added to the fuels and are detected by LIF in representation for the fuel [23]. However, care must be taken that the tracer and the fuel have very similar evaporation characteristics. Other fuel components such as aromatic compounds can directly be detected by LIF excitation using UV or even visible radiation [24]. Aromatics form an essential constituent of diesel, kerosene and heating oil and there are many studies in which these fuels have been measured by LIF $[19,25]$. For fundamental studies, acetone has frequently been used as a model fuel because of its well-known spectroscopic characteristics [26-28]. In concentration measurements with planar LIF of vaporized acetone close to a monodisperse droplet chain Stöhr et al. achieved a spatial resolution of $20 \mu \mathrm{m}$ [29]. It is noted that the high spatial resolution was only feasible at the expense of low signal strength.

In the study presented here, infrared (IR) laser absorption spectroscopy was applied to measure profiles of the mole fractions of different alkanes and butanol in the gas phase close to a monodisperse droplet chain. IR absorption spectroscopy is a well-established method to measure species concentrations and temperatures in various applications [30-33]. Usually compact tunable diode lasers are applied in different configurations. The beam profile of these lasers is only of moderate quality and therefore it is hardly possible to achieve a beam waist (and spatial resolution) of $100 \mu \mathrm{m}$ diameter by focusing the beam. In contrast, the infrared emission of a HeNe laser at $3.39 \mu \mathrm{m}$ can be exploited to excite the $\mathrm{CH}$ stretch band in hydrocarbon species [34-37]. HeNe lasers offer a better beam quality compared to diode lasers and the HeNe laser used in the current study was focused to a full width at half maximum (FWHM) of $50 \mu \mathrm{m}$ over a length of $2 \mathrm{~mm}$. Of course, absorption spectroscopy is a line-of-sight integrating method without spatial resolution in beam direction. In the application described in this paper, the droplet generator provided a very stable straight droplet chain moving in a laminar co-flow of air. Therefore, cylindrical symmetry was given and maintained over long measurement times. This enabled successive measurements at different radial dis- 
tances from the chain and the subsequent construction of radial species profiles. To the authors' knowledge this is the first demonstration of laser absorption spectroscopy for the measurement of hydrocarbon species evaporating from droplet chains.

The method was applied to droplet chains of cyclohexane, iso-octane, $n$-heptane, $n$-pentane and 1-butanol. The main motivation of the current paper is to present and demonstrate this measurement concept to characterize the evaporation of fuel droplets and to discuss its performance. In the long term, this technique will be combined with LIF to investigate the evaporation of twoor three-component fuels and to provide validation data for numerical simulations of the evaporation of multicomponent aviation fuels [38]. This is part of a research program at DLR focused on the design of alternative fuels.

\section{Experimental}

\subsection{Flow channel}

A schematic of the experimental setup is shown Fig. 1. Measurements were performed in a vertically arranged flow channel with a near quadratic cross-section of $62 \mathrm{~cm}^{2}$ and a height of $99 \mathrm{~cm}$. Optical access to the channel was provided by quartz plates on four sides held by a metal frame. Each plate had an open area of $240 \mathrm{~mm}$ x $60 \mathrm{~mm}$ and four of these optical segments were stacked upon each other. A reservoir for collecting the liquid fuel was installed at the bottom of the flow channel. The flow channel could be translated with step motors in vertical and horizontal directions. A module for providing a laminar gas flow was mounted at the top of the channel and on it a droplet chain generator (MTG-01-G3, FMP Technology GmbH). A monodisperse droplet chain was generated by Rayleigh decay of a liquid jet from an orifice plate of $75 \mu \mathrm{m}$ in diameter which was excited to vibrate by a piezoelectric ceramic actuator. The liquid fuel was supplied by a double-walled, pressure-tight stainless steel vessel and was pressurized with compressed air. Liquid mass flows between $1 \mathrm{~g} / \mathrm{min}$ and $3 \mathrm{~g} / \mathrm{min}$, measured with mini CORI-FLOW M13 (Bronkhorst), were used. Droplets were generated at frequencies between $10 \mathrm{kHz}$ and $75 \mathrm{kHz}$ and droplet diameters were between $120 \mu \mathrm{m}$ and $170 \mu \mathrm{m}$. The droplet spacing was varied between $298 \mu \mathrm{m}$ and $685 \mu \mathrm{m}$. Smaller spacings were not applied in order to avoid a disturbance of the laser beam on its pass between two successive droplets. The droplet velocity ranged from $8 \mathrm{~m} / \mathrm{s}$ to about $23 \mathrm{~m} / \mathrm{s}$.

The droplets were injected into the flow channel through a stainless steel tube of $60 \mathrm{~mm}$ length and $5 \mathrm{~mm}$ inner diameter. The tube was installed to separate the droplets from the inlet area of the gas for the channel flow and to prevent the droplet generator from becoming hot when the gas is preheated. The tube was not flushed with a gas flow. The temperature of the fluid was measured by a thermocouple located $5 \mathrm{~mm}$ above the orifice plate. A laminar and uniform flow of 2 standard $\mathrm{m}^{3} / \mathrm{h}$ of dry air 


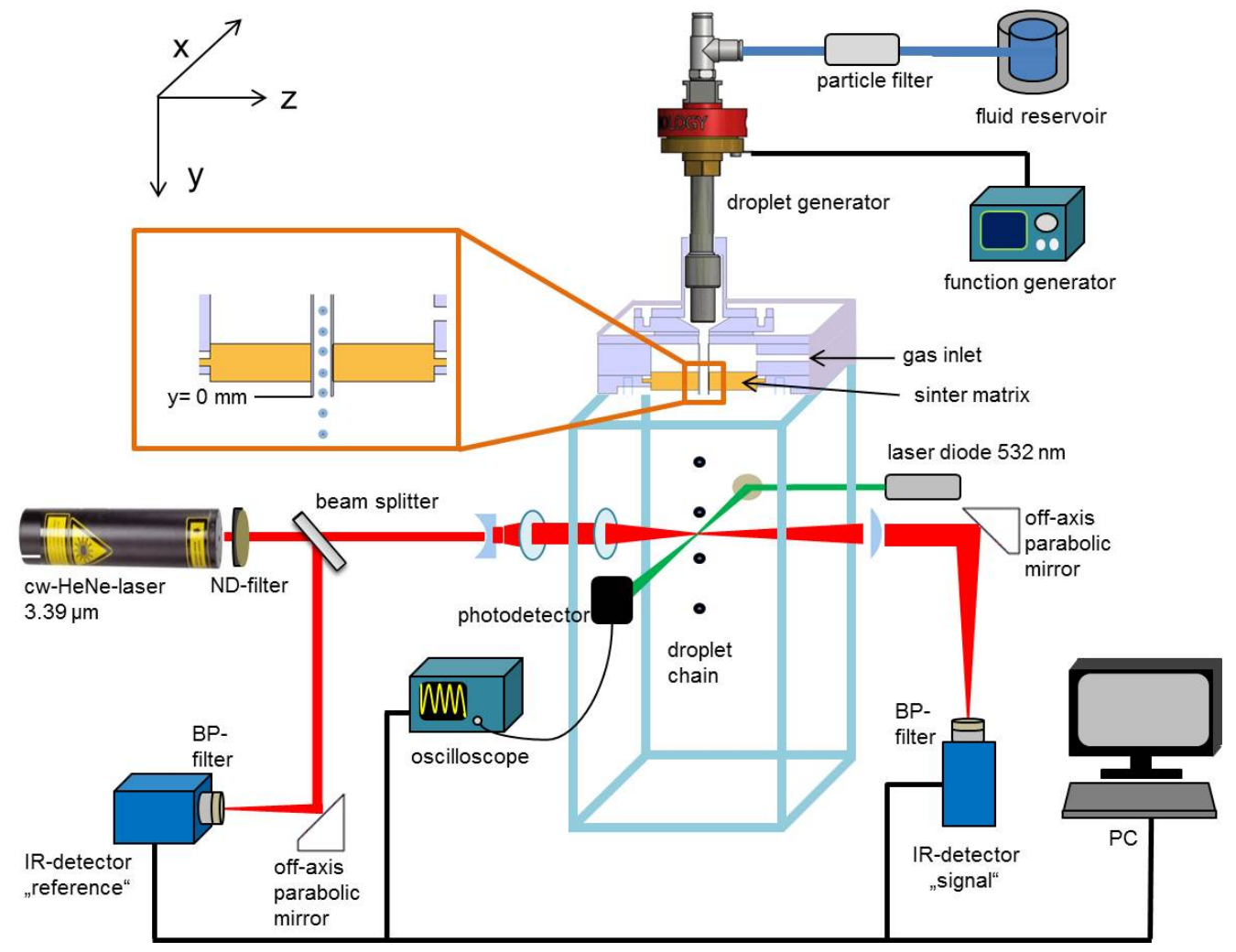

Fig. 1 Schematic of the experimental setup.

was obtained by homogenizing the flow with a porous sintered bronze plate $\left(60 \mathrm{x} 60 \mathrm{~mm}^{2}\right)$. The flow velocity in the channel was approximately $0.15 \mathrm{~m} / \mathrm{s}$ at $293 \mathrm{~K}$. The air was heated with an electrical heater (Osram, $4 \mathrm{~kW}$ ) to temperatures between $313 \mathrm{~K}$ and $423 \mathrm{~K}$.

The five fuels used in this investigation were cyclohexane, iso-octane, $n$-heptane, $n$-pentane, and 1-butanol and were purchased from VWR. Table 1 presents the list of the fuels tested.

\subsection{Optical setup and data acquisition}

Absorption measurements were performed with a cwHeNe laser (R-32172, Newport) operating at $3.39 \mu \mathrm{m}$. A neutral density filter (ND, OD 1.0, NDIR10B, Thor- labs) was used to attenuate the intensity of the laser light to avoid detector saturation. A beam splitter (silicon, $2^{\circ}$ wedge, WW81050, Thorlabs) was used to direct a fraction of the light to a reference detector (PVI-3TE-5, Vigo Systems). Visible laser light from a diode (CPS532C2, $532 \mathrm{~nm}$, Thorlabs) was aligned collinear with the IR beam with the same beam splitter to simplify alignment of the IR beam. A beam expander telescope $\left(\mathrm{CaF}_{2}, \mathrm{f}=\right.$ $-25 \mathrm{~mm}, \mathrm{f}=50 \mathrm{~mm}$ ) was installed to expand the beam to a diameter of $6 \mathrm{~mm}$. Then the beam was focused into the flow channel by a $\mathrm{CaF}_{2}$ lens with $\mathrm{f}=80 \mathrm{~mm}$. The laser beam diameter in the center of the flow channel was measured with the knife-edge technique. The FWHM of the focused laser beam was $50 \mu \mathrm{m}$ over a length of $2 \mathrm{~mm}$. Af- 
Table 1 List of the fuels examined including some of their chemical and physical properties. The diffusion coefficient is for fuel vapor in air at $298 \mathrm{~K}$ [39]. The values for the boiling point and enthalpy of vaporization are from [40]. The last column refers to the gas cell measurements described below.

\begin{tabular}{cccccccc}
\hline Fuel species & Formula & Hydrocarbon & Purity & Boiling & Enthalpy of & Diffusion & Fuel mole fraction \\
& & qualification & & point & vaporization & coefficient & range for cross section \\
& & & & {$[\mathrm{K}]$} & {$[\mathrm{kJ} / \mathrm{mol}]$} & {$\left[\mathrm{cm}^{2} / \mathrm{s}\right]$} & measurements [mol\%] \\
\hline \multirow{2}{*}{ cyclohexane } & $\mathrm{C}_{6} \mathrm{H}_{12}$ & cycloalkane & $\geq 99.5 \%$ & 353.9 & 33.1 & 0.08455 & $0.21-1.48$ \\
iso-octane & $\mathrm{C}_{8} \mathrm{H}_{18}$ & branched alkane & $\geq 99.5 \%$ & 372.4 & 35.1 & 0.06338 & $0.15-2.01$ \\
n-heptane & $\mathrm{C}_{7} \mathrm{H}_{16}$ & straight alkane & $\geq 99.0 \%$ & 371.5 & 36.0 & 0.06759 & $0.2-2.06$ \\
n-pentane & $\mathrm{C}_{5} \mathrm{H}_{12}$ & straight alkane & $\geq 99.0 \%$ & 309.2 & 26.5 & 0.08441 & $0.44-1.56$ \\
1-butanol & $\mathrm{C}_{4} \mathrm{H}_{10} \mathrm{O}$ & alcohol & $\geq 99.5 \%$ & 390.6 & 52.0 & 0.08632 & $0.14-0.88$ \\
\hline
\end{tabular}

ter passing the flow channel the laser light was collimated by a $\mathrm{CaF}_{2}$ lens with $\mathrm{f}=75 \mathrm{~mm}$ and focused onto the signal detector with an off-axis parabolic mirror (MPD129M01, Thorlabs). Band pass filters (BP, CW $=3250 \mathrm{~nm}$; FWHM $=500 \mathrm{~nm}$, Thorlabs) were installed in front of each detector. Absorption measurements were performed between $\mathrm{y}=5 \mathrm{~mm}$ and $50 \mathrm{~mm}$ under the tube exit at four heights. At larger y-values the coherent structure of the droplet chain was reduced so that uncertainties in the position increased.
Further, laser radiation at $\lambda=532 \mathrm{~nm}$ (CPS532-C2, Thorlabs) was used to permanently monitor the stability of the droplet chain and provide a trigger signal. This laser was fixed at the flow channel and therefore not translated relative to the droplet chain, when the flow channel was moved. The beam of this "trigger" laser was focused on the droplet chain perpendicular to the IR beam and the transmitted intensity was monitored with a photodiode (PDA36A-EC, Thorlabs).

Data acquisition was based on a LabVIEW program using a data acquisition board (National Instruments 
Inc., PCI 6115, $10 \mathrm{MS} / \mathrm{s})$. Signals of the two IR detectors (signal and reference) and the photodiode of the visible laser were acquired simultaneously. The measurement duration at each location was $1 \mathrm{~s}$ at a sampling rate of $10 \mathrm{MS} / \mathrm{s}$.

To obtain information about the boundary conditions relevant for the interpretation of the results, the temperatures in the vicinity of the droplet chain were determined by $250 \mu \mathrm{m}$ K-type thermocouples at different $\mathrm{x}$ and y-positions in the flow channel. Further, droplet sizes and velocities were measured using shadowgraphy. A pulsed LED (pulse length 50 ns, LM2xLZ DMHP, Innovative Scientific Solutions) was used as the light source. The transmitted light was recorded by a CCD camera (Imager Intense, LaVision) equipped with a macro lens (MP-E-65 mm, f/2.8, Canon). The spatial resolution of the imaging system was $3.7 \mu \mathrm{m} / \mathrm{px}$.

\subsection{Heated gas cell for absorption cross section}

measurements

To determine absolute concentrations of the fuel vapor, the temperature-dependent absorption cross sections of the fuels must be known. They were determined in this study using a gas cell and the same laser setup and detection scheme as for the droplet chain measurements. The experimental setup is shown schematically in Fig. 2 .

The heated quartz gas cell had a length of $100 \mathrm{~mm}$, an inner diameter of $10 \mathrm{~mm}$ and was equipped with quartz windows (wedge angle $2^{\circ}$ ) on both sides. The gas cell was encased in a stainless steel tube wrapped with a heating cord (HSQ, Horst GmbH) and insulated with glass wool. The length of the heated section was $300 \mathrm{~mm}$. The temperature of the test cell was monitored using a K-type thermocouple on the outside. Two thermocouples in the gas inlet and outlet of the cell were used to ensure a homogeneous temperature distribution. Measurements were performed between 300 and $773 \mathrm{~K}$ at atmospheric pressure.

The cell was operated in a continuous flow mode. Mixture preparations for gases were performed in the following manner. The carrier gas $\mathrm{N}_{2}$ streamed through two gas wash bottles, which were filled with the examined liquid fuel. A second $\mathrm{N}_{2}$ line was used to dilute the fuel vapor $/ \mathrm{N}_{2}$ mixture coming from the wash bottles and to set a defined mixture. The mixture entered the gas cell and then passed through a binary gas analyzer (BGA 244HP, Stanford Research Systems) to determine the actual concentration of the gas mixture by measuring the speed of sound of the gas. The range of concentrations used for each fuel is shown in Table 1.

The same laser and data acquisition system described above was used for the measurements. Prior to each absorption measurement, the test cell was filled with $\mathrm{N}_{2}$ and the signal intensities of both detectors were recorded. Then, the gas mixture was introduced into the cell and once the vapor concentration was stabilized the reference and signal detector intensities were recorded over $1 \mathrm{~s}$ at a sampling rate of $10 \mathrm{MS} / \mathrm{s}$. 


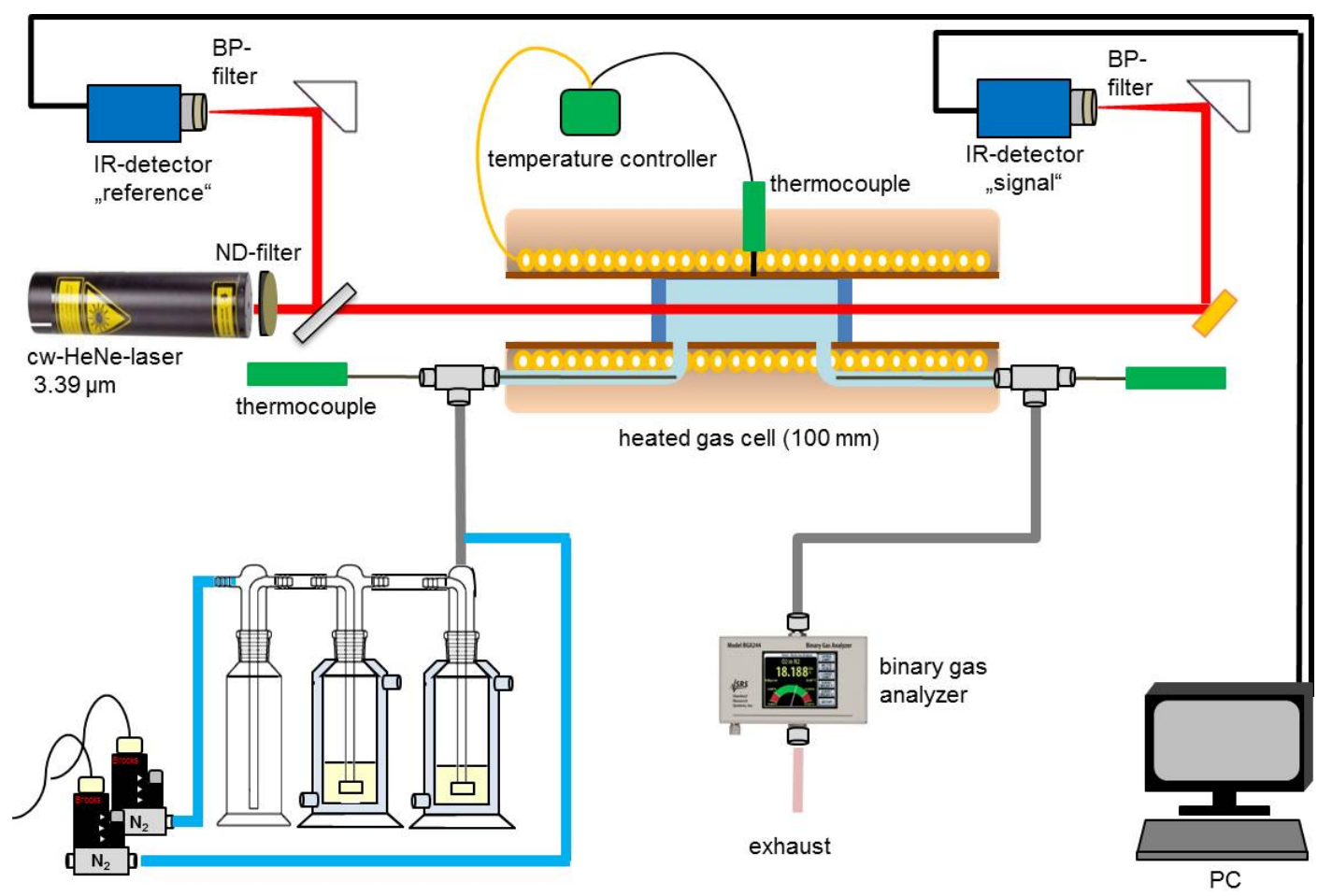

Fig. 2 Experimental setup for the absorption cross section measurements in a heated gas cell.

\section{Data analysis and uncertainty}

\subsection{Principles of absorption spectroscopy}

Detailed descriptions about absorption spectroscopy can

be found in the literature $[30,41,42]$. Therefore, only the relationships relevant for this investigation are briefly presented here. The absorption $A$ is calculated from the initial laser intensity $I_{0}$ and the transmitted intensity $I$ with the Beer-Lambert law

$$
A=-\ln \left(\frac{I}{I_{0}}\right)=\sigma(T) N d
$$

where $\sigma(\mathrm{T})$ is the temperature-dependent absorption cross section, $d$ is the path length and $N$ is the molar density of the species in units of $\mathrm{mol} / \mathrm{m}^{3}$. Since in this investigation a reference detector was used to capture laser energy fluctuations, the absorption is expressed as follows

$$
A=-\ln \left(\frac{I_{0 r e f}}{I_{r e f}} \cdot \frac{I_{s i g}}{I_{0 s i g}}\right)
$$

where "ref" subscripts the signal of the reference detector and "sig" subscripts the signal of the signal detector.

For the determination of the absorption cross sections the measured absorption per path length is plotted as a function of the molar density $(f(N)=A / d)$. The slope can then be used to determine the absorption crosssection $\sigma . N$ is calculated with the ideal gas law

$$
p \cdot x_{i}=p_{i}=N_{i} R T
$$


where $p$ is the total pressure in the gas cell, $x_{i}$ the mole fraction, $p_{i}$ the partial pressure, $R$ the ideal gas constant and $T$ the temperature. The error in $N$ is calculated from the error in $p(1 \%), T( \pm 2.5 \mathrm{~K})$ and $x_{i}(0.006$ $-0.011 \mathrm{~mol} \%)$. The uncertainty in $\sigma$ is determined from the linear regression and is between 0.5 and $3 \%$ for the investigated fuels.

\subsection{Absorption measurements at droplet chains}

In Fig. 4 the steps to convert the raw intensity signals into radial concentration profiles are shown for two distances $\Delta \mathrm{x}$ of the laser beam from the droplet chain center line (see also Fig. 3).

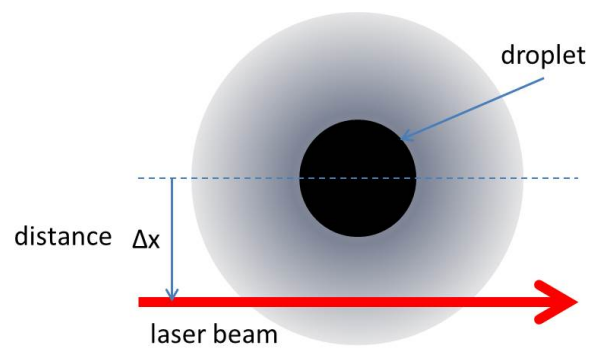

Fig. 3 Schematic geometric arrangement of the laser beam and droplets as well as definition of distance $\Delta \mathrm{x}$.

The plots in the left column correspond to a distance of $0.1 \mathrm{~mm}$ between the laser beam and the droplet chain center line, while for those in the right column the laser beam intersects the droplet chain center line $(\mathrm{x}=$ $0 \mathrm{~mm}$ ). The top row (a) displays the temporal raw intensity traces of the absorption signal, the reference signal and the trigger signal. From the trigger signal it is clearly seen, that every $0.084 \mathrm{~ms}$ a droplet passes through the a)

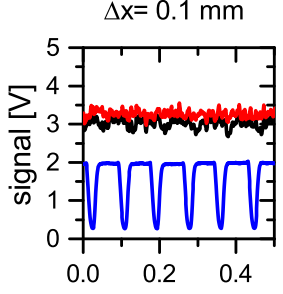

b)
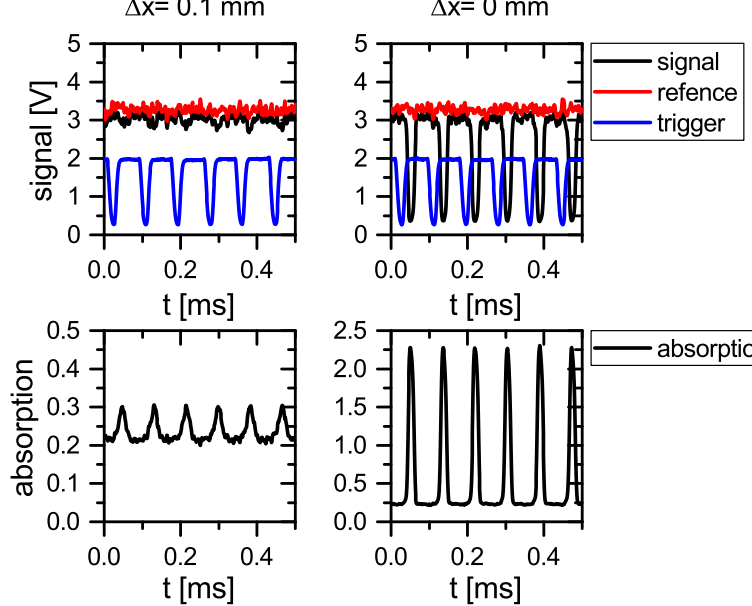

$\mathrm{t}[\mathrm{ms}]$

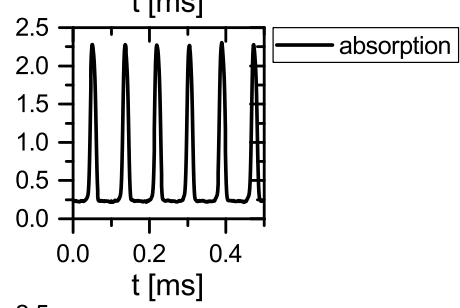

c)
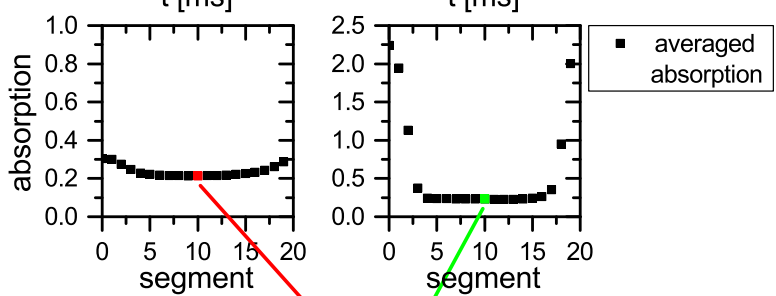

d)

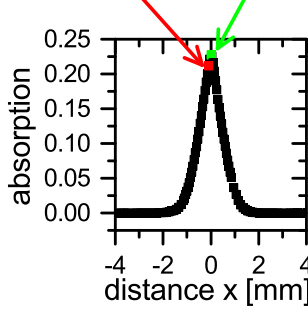

e)

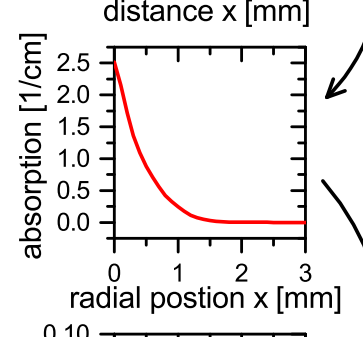

Abel Inversion

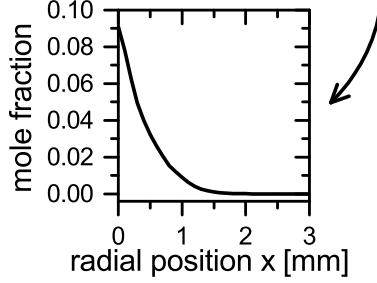

$\sigma(\mathrm{T}), \mathrm{T}, \mathrm{p}$

f)

$$
\text { radial position } \times[\stackrel{3}{\mathrm{~mm}}]
$$

Fig. 4 Illustration of the evaluation routine to compute radial profiles of absolute fuel vapor concentrations using cyclohexane as example.

green laser beam. At a distance of $\Delta \mathrm{x}=0.1 \mathrm{~mm}$ from the droplet chain center line the absorption signal exhibits a relatively constant value, which is slightly modulated 
by the passing droplets. The signal on the center line (right column) is, in contrast, strongly modulated. This is not surprising because the IR laser beam is strongly absorbed and deflected when it hits a droplet.

First, the raw signal intensities in Fig. 4 (a) were converted into absorption signals using equation 2 . The resulting absorption signals are shown in the second row (b). When comparing (a) and (b) it is seen that variations due to laser intensity fluctuations are efficiently compensated by ratioing to the reference signal. In the left column in Fig. 4 (b) the absorption signal varies periodically between approximately 0.22 and 0.3 and in the right column between approximately 0.25 and 2.25 . The larger absorption value coincides with the point in time when a droplet passes by and the smaller value is between two successive droplets.

As a next step a peak finding algorithm is used either directly with the absorption signal or using the signal of the green trigger laser for distances where the HeNe laser does not hit the droplet chain. The time interval from one peak to the next (from droplet to droplet) is referred to here as period and is equal to $0.084 \mathrm{~ms}$ in the example of Fig. 4. The absorption trace of each period is divided into 20 segments and the signals within each segment are averaged to yield one data point (row (c) in Fig. 4). Segment 0 corresponds to the time when a droplet is at the height of the laser beam and segment 10, for example, corresponds to the time when the laser beam lies in the middle between two droplets. Depend- ing on the droplet frequency about 10000 to 75000 data points were averaged for each segment over the measurement time of $1 \mathrm{~s}$. In this way, mean absorption traces are calculated for each distance $\Delta \mathrm{x}$ at which measurements were performed (typically 150). The absorption at each segment of the mean trace can then be plotted against the distance $\Delta \mathrm{x}$, as illustrated in Fig. 4 (d) for segment 10.

Because the droplet chain is cylindrical symmetric the line-of-sight integrated absorption can be converted into radial absorption profiles using Abel inversion. First, the absorption profiles were mirrored and then transformed into radial profiles using the three-point Abel inversion method of Dasch [43] to obtain the absorption per path length (see Fig. $4(\mathrm{e})$ ). Using the temperatures measured with thermocouples, the temperaturedependent absorption cross section and the total pressure, radial absorption profiles were converted into concentration profiles, as shown in Fig. 4 (f). Due to the evaporation of the liquid, the temperature is slightly lower close to the droplets than in the surrounding gas flow. The maximum difference is $30 \mathrm{~K}$ for a gas temperature of $427 \mathrm{~K}$. For cyclohexane, which has the strongest dependence of the absorption cross section on temperature (see Fig. 5(b)), an error in temperature of $30 \mathrm{~K}$ would cause an error in the the measured mole fraction of $10 \%$. For the other hydrocarbons investigated the error is negligible. 


\section{Results and discussion}

First, the absorption cross sections measured for the investigated single-component fuels are presented. Second, the measured absorption profiles of the droplet chain of different fuels are shown. Third, the resulting mole fraction profiles are discussed and finally comparisons are made between the different fuels.

\subsection{Absorption cross sections of single-component hydrocarbon fuels}

Fig. 5 (a) presents the absorption $A / d$ as a function of the molar density for the given fuels at $473 \mathrm{~K}$. The absorption is averaged over $1 \mathrm{~s}$ and the corresponding standard deviation is $0.06 \mathrm{~m}^{-1}$ and therefore in all cases less than $2 \%$. The molar density was varied between 0.03 and $0.37 \mathrm{~mol} / \mathrm{m}^{3}$ which corresponds to mole fractions of $0.15 \mathrm{~mol} \%$ up to $2.06 \mathrm{~mol} \%$ in the cell. Measured absorption values were between 0.1 and 2.1 for the given absorption path of length $0.1 \mathrm{~m}$. The results show the expected linear relationship between absorption and molar density. The slope of the linear fit through the data points corresponds to the absorption cross section. The uncertainty in the cross section was determined from the error in the slope and is $<3 \%$. The measurements were performed in the temperature range $300 \mathrm{~K}-773 \mathrm{~K}$ for all investigated compounds and the resulting absorption cross section values are shown in Fig. 5 (b).
In general, the absorption cross-section increases with increasing $\mathrm{C}-\mathrm{H}$ bonds in the fuel molecule. The effect of temperature on the absorption cross section is small except for cyclohexane. The cyclohexane absorption cross section decreased from $300 \mathrm{~K}$ to $773 \mathrm{~K}$ by $33 \%$. This behavior was also observed by Tomita et al.. For all other fuels the cross section only changes between $10 \%$ to $15 \%$. The measured cross-sections show good agreement with the available literature data [44-47]. For 1-butanol no reliable literature data could be found.

\subsection{Absorption measurements on a droplet chain}

In Fig. 6 examples for absorption profiles of cyclohexane are shown at different axial positions y and distances $\mathrm{x}$ from the droplets at $313 \mathrm{~K}$ gas temperature and at a droplet injection frequency of $11.9 \mathrm{kHz}$ are shown. The droplet diameter at $\mathrm{y} \approx 0$ was about $160 \mu \mathrm{m}$ and the droplet velocity was $8.1 \mathrm{~m} / \mathrm{s}$. Measurements were performed at heights of $\mathrm{y}=5 \mathrm{~mm}, \mathrm{y}=20 \mathrm{~mm}, \mathrm{y}=35 \mathrm{~mm}$ and $\mathrm{y}=50 \mathrm{~mm}$ below the tube exit (see Fig. 1 ).

In the middle column $2 \mathrm{D}$ absorption plots for the different measurements are shown deduced from the 20 segments of a period. The values between the points were determined by linear interpolation. Here, the 20 segments of a period are converted to the distance between the droplets for clarity. Segment 0 was assigned to $0 \mu \mathrm{m}$ and segment 20 to $680 \mu \mathrm{m}$. The distance was determined by shadowgraphy and is about $680 \mu \mathrm{m}$. The high absorption values shown as white areas are due to 
a)

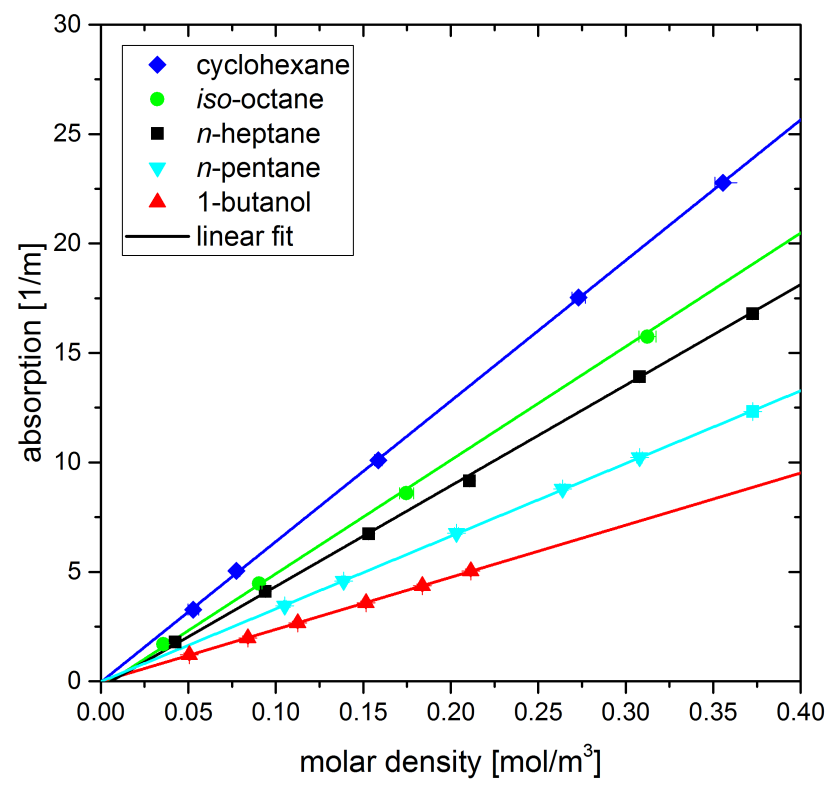

b)

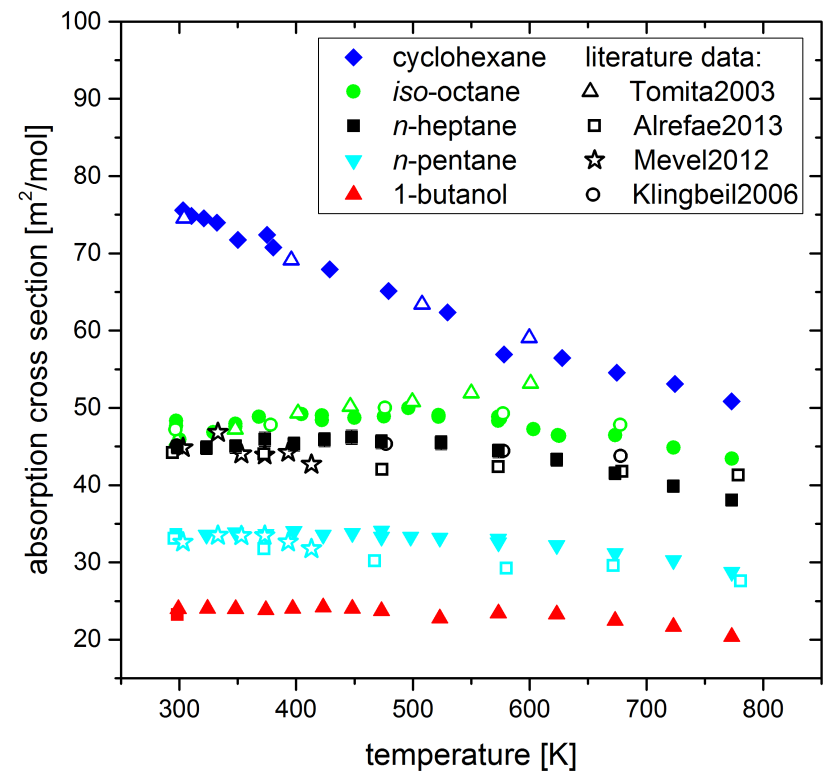

Fig. 5 (a) Absorption as a function of the molar density for the investigated fuels at $473 \mathrm{~K}$ and the laser wavelength of $3.392 \mu \mathrm{m}$. (b) The effect of temperature on the absorption cross sections of single-component fuels. Open symbols correspond to literature data.

strong absorption and deflection when the droplets pass through the laser beam. Close to the center line, noticeable changes of the absorption in axial direction y are seen, however, they smooth out quickly at distances $\Delta \mathrm{x}$ $\geq 0.25 \mathrm{~mm}$. This means that the cloud of evaporated fuel does not respond to the actual position of the droplet, at least not for $\Delta \mathrm{x} \geq 0.25 \mathrm{~mm}$.

In the right column the horizontal absorption profiles are displayed for the four heights against the distance $\Delta \mathrm{x}$ to the droplet chain center line. They correspond to the position in the middle between two droplets (segment 10 in Fig. 4).

In the left column the vertical absorption profiles at the center line at $\mathrm{x}=0 \mathrm{~mm}$ are displayed for the four heights. As can be seen the absorption between two droplets by a gas flow and thus vapor can accumulate inside the is slightly asymmetric. After the droplet has passed the laser beam (at about $150 \mu \mathrm{m}$ or $\mathrm{t}=0.013 \mathrm{~ms}$ ) the trailing of the vapor is visible in the absorption signal. The absorption decreases until about $400 \mu \mathrm{m}(\mathrm{t}=0.05 \mathrm{~ms})$. When the next droplet arrives the absorption signal rises steeply until the laser beam is clipped by the liquid droplet.

The corresponding radial profiles of the mole fractions are shown in Fig. 7. The peak mole fractions at $x=0$ are on the order of 0.09 , even at the smallest distance of $\mathrm{y}=5 \mathrm{~mm}$ from the exit of the tube. This relatively high "start" mole fraction is explained by the evaporation within the tube between the injector and the entrance into the flow channel. The tube is not flushed 

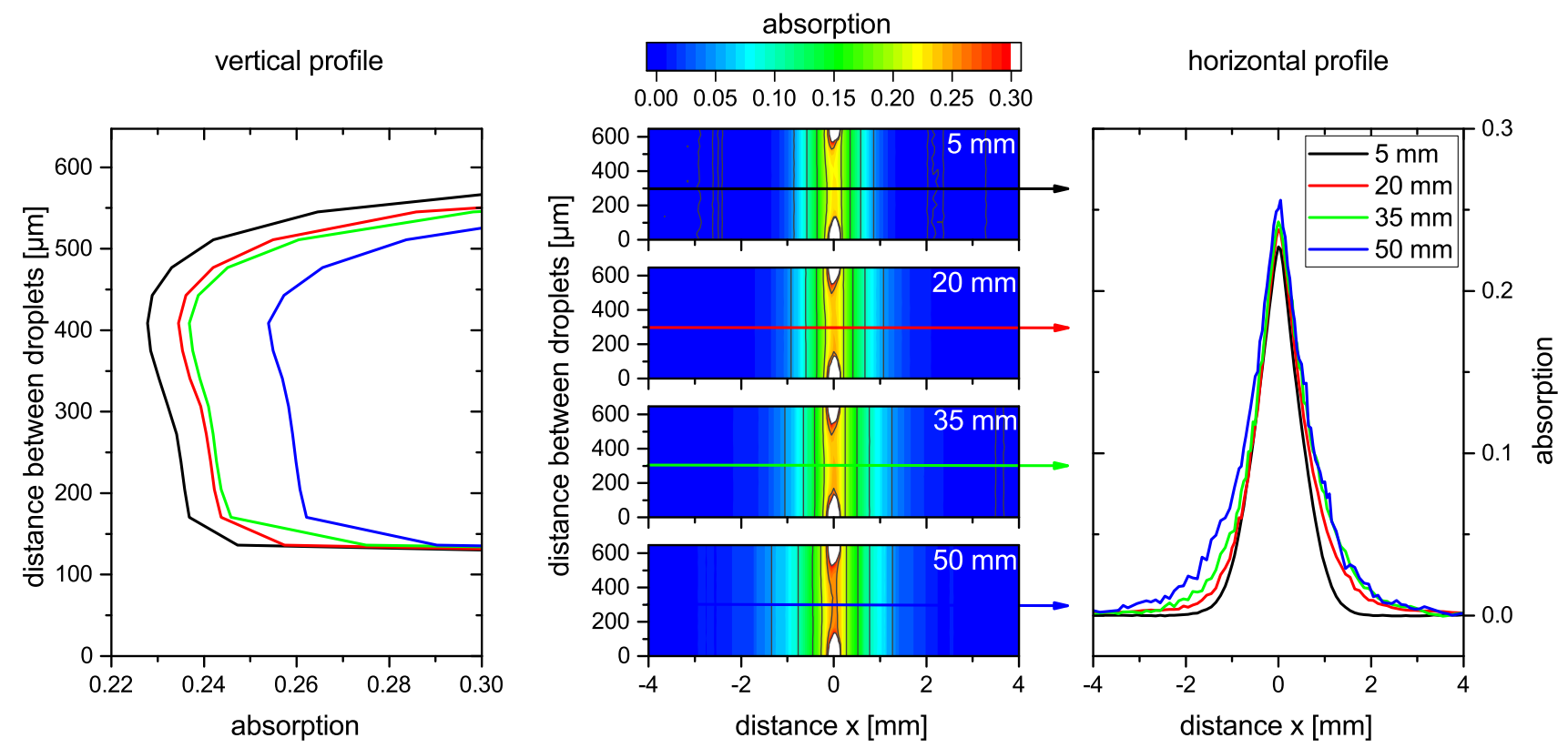

Fig. 6 Results of absorption measurements of cyclohexane at axial positions $y=(5,20,35$ and 50$)$ mm at a droplet injection rate of $11.9 \mathrm{kHz}$ and a gas temperature of $313 \mathrm{~K}$.

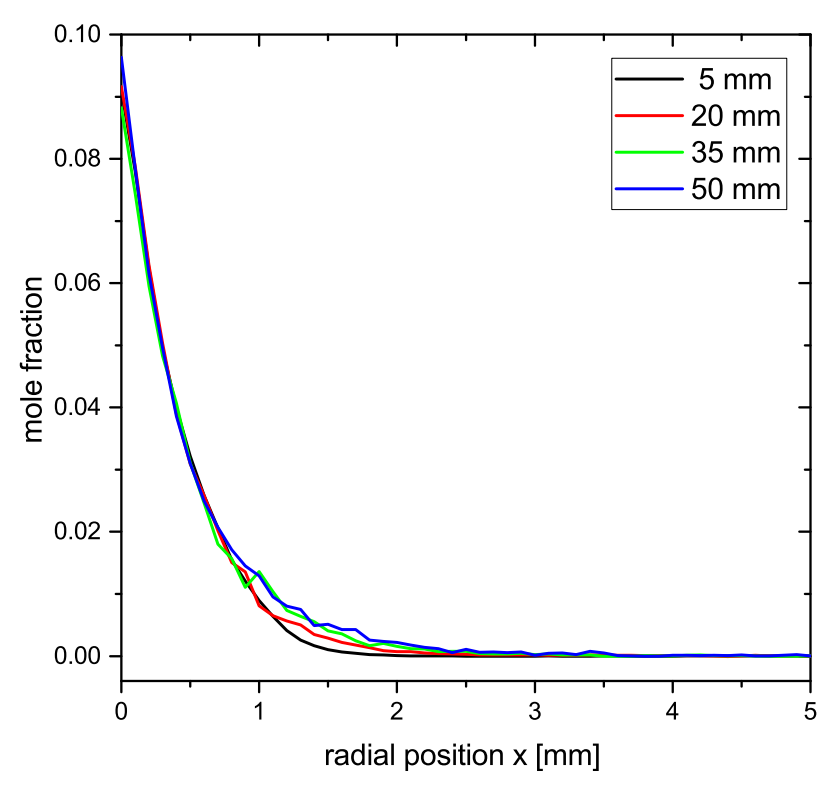

Fig. 7 Radial profiles of the mole fraction of cyclohexane at different axial positions y.

tube. A portion of the vapor is continuously entrained and carried along by the droplet chain. The vapor pressure of cyclohexane at $313 \mathrm{~K}$ is approximately $24 \mathrm{kPa}$
[48]. This corresponds to a mole fraction of cyclohexane in air of about 0.24 . The comparison with the measured mole fraction of 0.09 shows that the gas surrounding the droplet chain is by far not saturated with cyclohexane. The mole fraction rapidly drops with increasing radial distance and at $\mathrm{x} \approx 1 \mathrm{~mm}$ it is on the order of 0.01 . A comparison of the radial profiles at different heights reveals that they are quite similar up to $\mathrm{x} \approx 0.7 \mathrm{~mm}$ and that noticeable differences occur for larger radii. These differences can be explained by progressive evaporation and diffusion of the fuel with increasing distance from the nozzle exit. The standard deviation of the absorption is $4 \cdot 10^{-3}$. If this is taken as the noise level, for the results shown in Fig. 8 at $313 \mathrm{~K}$ the signal-to-noise ratio is about 60 at the peak and the minimal measurable mole fraction at $1 \mathrm{~mm}$ path length would be $1 \cdot 10^{-3}$. 
a)

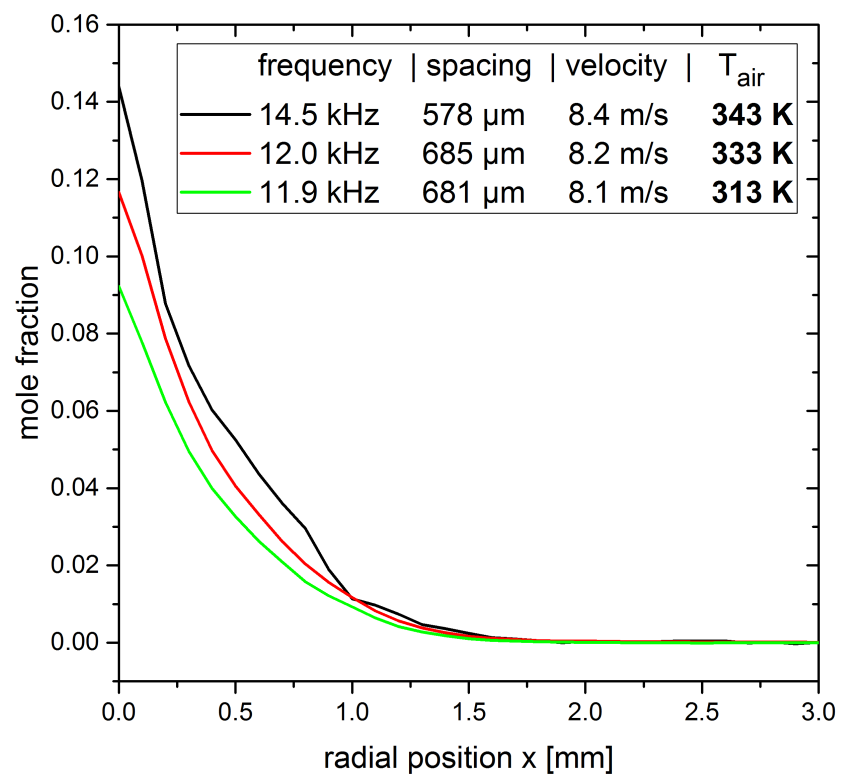

b)

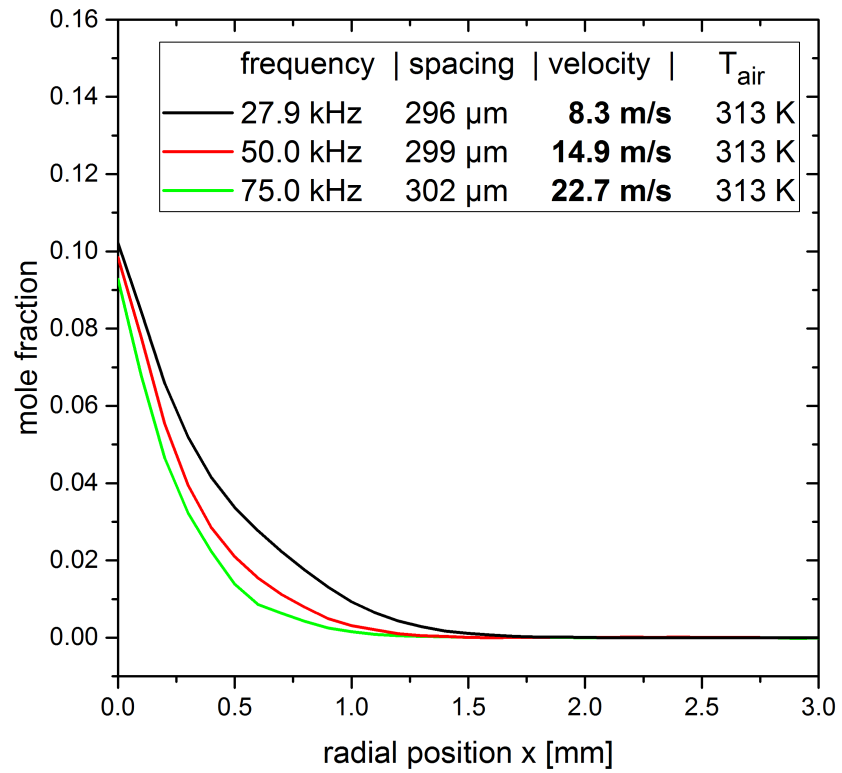

Fig. 8 Radial profiles of the mole fractions of cyclohexane at a fuel mass flow of $\sim 1.2 \mathrm{~g} /$ min for different gas temperatures (a) and different droplet velocities, respectively different mass flows, at same temperature (b) at $\mathrm{y}=5 \mathrm{~mm}$. The profiles correspond to the position in the middle between two droplets.

In Fig. 8(a) radial mole fraction profiles of cyclohexane are shown for different coflow temperatures at the measurement position $\mathrm{y}=5 \mathrm{~mm}$. As expected, the mole fraction increases with increasing temperature. The widths of the profiles remain however more or less the same, i.e. the mole fraction reaches zero at about $\mathrm{x}=$ $1.5 \mathrm{~mm}$ regardless of the temperature. This may be explained by the flow field at the exit of the tube.

In addition to the gas temperature also the fuel mass flow and therefore the speed of the droplets was varied, while keeping the gas flow speed constant. As can be seen in Fig. 8 (b) the profiles become narrower with increasing droplet speed, because the residence time of the droplet decreases so that less time is available for evaporation and diffusion.

\subsection{Comparison between different fuels}

The data from the four measurement planes enables the calculation of the increase of evaporated fuel with axial position y or time. In a first step, the fuel mole fractions are integrated over the cross sectional area at the axial measurement positions y exploiting the cylindrical symmetry of the setup. For the comparison of results at different gas temperatures it is more convenient to use the fuel particle number density instead of the fuel mole fraction. The integration then yields the particle number per unit axial length. With integration along y, along the droplet chain, one would get the total particle number in the vapor cloud around the droplet chain. Fig. 9 (a) shows this particle number per length as function of ax- 
ial position $y$ and Fig. 9 (b) as a function of droplet time of flight for selected measurement conditions of cyclohexane. The different symbols correspond to different temperatures. Droplet velocities of $8-23 \mathrm{~m} / \mathrm{s}$ correspond to time-of-flight times of $22-62 \mathrm{~ms}$ at $\mathrm{y}=50 \mathrm{~mm}$. The total particle number increases linearly over time and the slope is therefore a measure for the evaporation rate. As can be seen the evaporation rate is dominated by the temperature, while droplet velocity and the spacing between droplets have only minimal influence. However the velocity has significant influence on the absolute particle numbers. At about $8 \mathrm{~m} / \mathrm{s}$ the particle numbers are more than a factor of two larger than at $22.7 \mathrm{~m} / \mathrm{s}$. This trend could already be seen in Fig. 8 (b). In contrast, the distance between droplets has only a small influence on absolute particle numbers.

In this comparison it must be taken into account that at fixed droplet velocity, which is connected to a constant mass flow, the injection frequency and droplet spacing are coupled. Therefore smaller injection frequencies cause larger droplet diameters and larger droplet spacings. While a larger droplet spacing is expected to lead to an increase of the evaporation rate [49], the combined effect of smaller frequency and larger diameter leads to a smaller total droplet surface which tends to decrease the evaporation rate. As a result of this counter balancing effects, the variations of the droplet spacing has only a minimal influence on the evaporation rate, as seen in Fig. 9 (a).
It is noted that the droplet diameter decreased only by a few micrometers between $\mathrm{y}=5 \mathrm{~mm}$ and $50 \mathrm{~mm}$. Therefore, a determination of the evaporation rate using the droplet diameter could not be performed reliably under the prevailing experimental conditions.

The evaporation rates obtained from the total particle numbers per unit length are displayed in Fig. 10 for all investigated conditions and fuels as a function of coflow temperature. Only one data point could be obtained for $n$-pentane. Because of its physical properties, e.g. low dynamic viscosity of $0.25 \mathrm{mPas}$ at $293 \mathrm{~K}$ and the low boiling temperature of $309 \mathrm{~K}$ only one condition was measured. With increasing temperature the viscosity of $n$-pentane decreases and therefore no stable monodispersed droplet chain for temperatures above room temperature could be obtained.

The relationship between evaporation rate and temperature is well described with a linear fit, at least for the temperature range between $313 \mathrm{~K}$ and $430 \mathrm{~K}$. Because droplet velocity and spacing have only a minor influence on the evaporation rate, the corresponding data points are not marked differently in the plot. The differences in the evaporation behaviour between the fuels are clearly seen. The order of the fuels is in accordance with the boiling points of the fuels (1-butanol $\gg$ iso-octane $>n$-heptane $\gg$ cyclohexane $\gg n$-pentane). Iso-octane and $n$-heptane have very similar boiling points and heats of evaporation (see Table1). The slightly higher evaporation rate of $n$-heptane in comparison to iso-octane 
a)

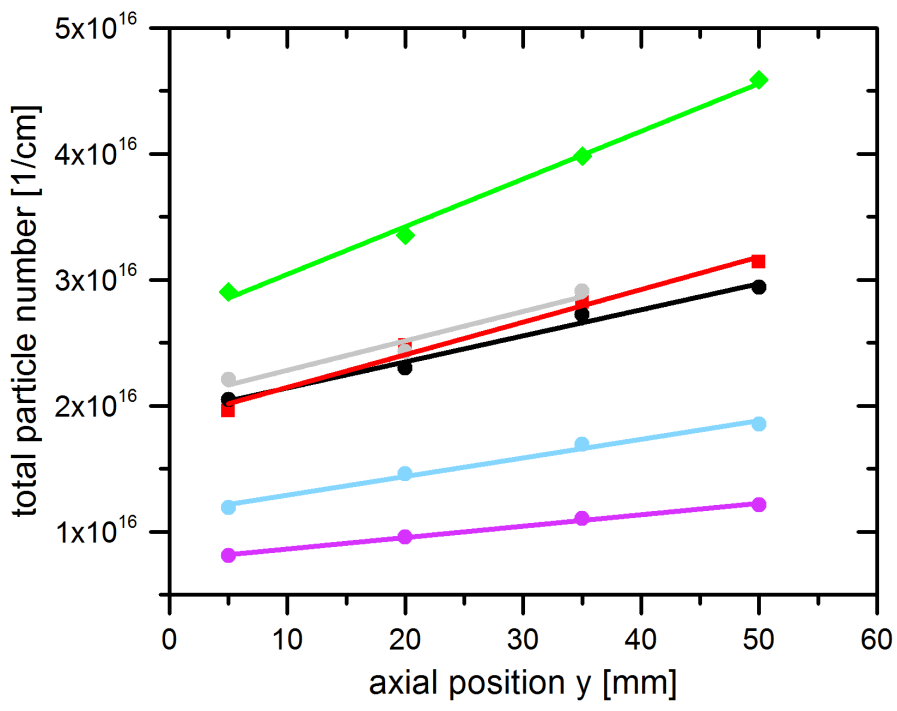

\begin{tabular}{|c|c|c|c|c|c|c|c|c|c|}
\hline & frequency & spacing & | velocity & $\mathrm{T}_{\text {air }}$ & & frequency & spacing & velocity | & $\mathrm{T}_{\text {air }}$ \\
\hline$\bullet$ & $40.0 \mathrm{kHz}$ & $468 \mu \mathrm{m}$ & $18.7 \mathrm{~m} / \mathrm{s}$ & $427 \mathrm{~K}$ & $\bullet$ & $11.9 \mathrm{kHz}$ & $681 \mu \mathrm{m}$ & $8.1 \mathrm{~m} / \mathrm{s}$ & $314 \mathrm{~K}$ \\
\hline - & $31.0 \mathrm{kHz}$ & $591 \mu \mathrm{m}$ & $18.3 \mathrm{~m} / \mathrm{s}$ & $382 \mathrm{~K}$ & • & $50.0 \mathrm{kHz}$ & $299 \mu \mathrm{m}$ & $14.9 \mathrm{~m} / \mathrm{s}$ & $314 \mathrm{~K}$ \\
\hline - & $27.9 \mathrm{kHz}$ & $296 \mu \mathrm{m}$ & $8.3 \mathrm{~m} / \mathrm{s}$ & $314 \mathrm{~K}$ & $\bullet$ & $75.0 \mathrm{kHz}$ & $302 \mu \mathrm{m}$ & $22.7 \mathrm{~m} / \mathrm{s}$ & $314 \mathrm{~K}$ \\
\hline
\end{tabular}

b)

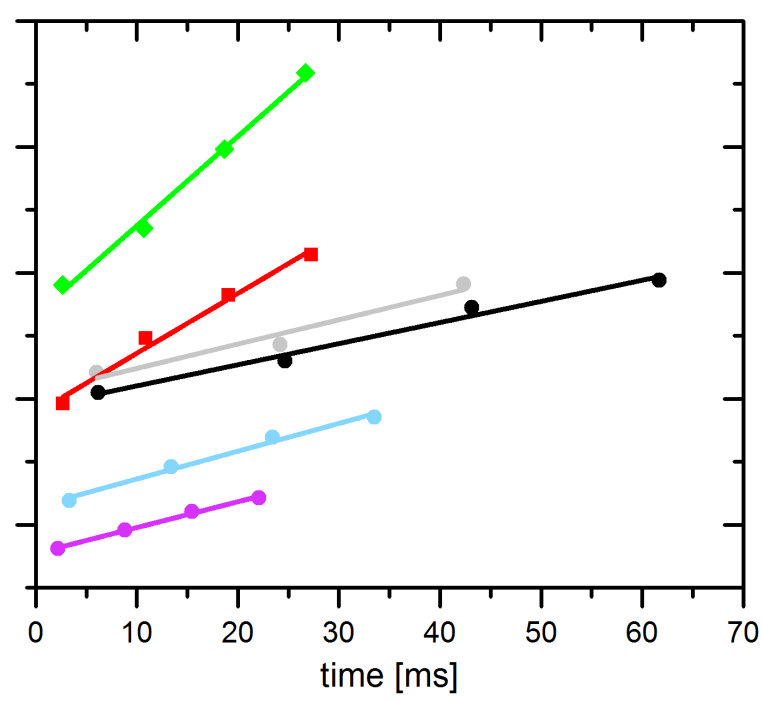

Fig. 9 Cyclohexane particle number per unit length for different experimental conditions as a function of axial position y (a) and droplet flight time (b).

may be explained by the slightly lower boiling point (by $0.9 \mathrm{~K})$ in combination with a larger diffusion coefficient.

\section{Summary and Conclusions}

An experimental setup for the study of droplet evaporation at a monodisperse droplet chain within a flow channel has been presented. IR laser absorption spectroscopy was applied to measure the vapor concentrations of cyclohexane, iso-octane, $n$-heptane, $n$-pentane, and 1-butanol. The influence of experimental parameters such as droplet velocity, inter-droplet distance and coflow temperature on the evaporation was determined. The results comprise vapor concentration profiles at dif- ferent axial locations, evaporation rates in dependence of coflow temperature and a comparison of the fuels. Under the present experimental conditions the evaporation rates increased linearly with temperature in the investigated temperature range $(313 \mathrm{~K}-430 \mathrm{~K})$. The order of the fuels with respect to evaporation rates corresponded with the boiling points of the individual fuels. Further, the absorption cross sections at $\lambda=3.392 \mu \mathrm{m}$ of the fuels used were determined in a heated cell in a temperature range between $300 \mathrm{~K}$ and $773 \mathrm{~K}$. A main aspect of the investigation was an evaluation of the performance of laser absorption spectroscopy for the study of evapora- 


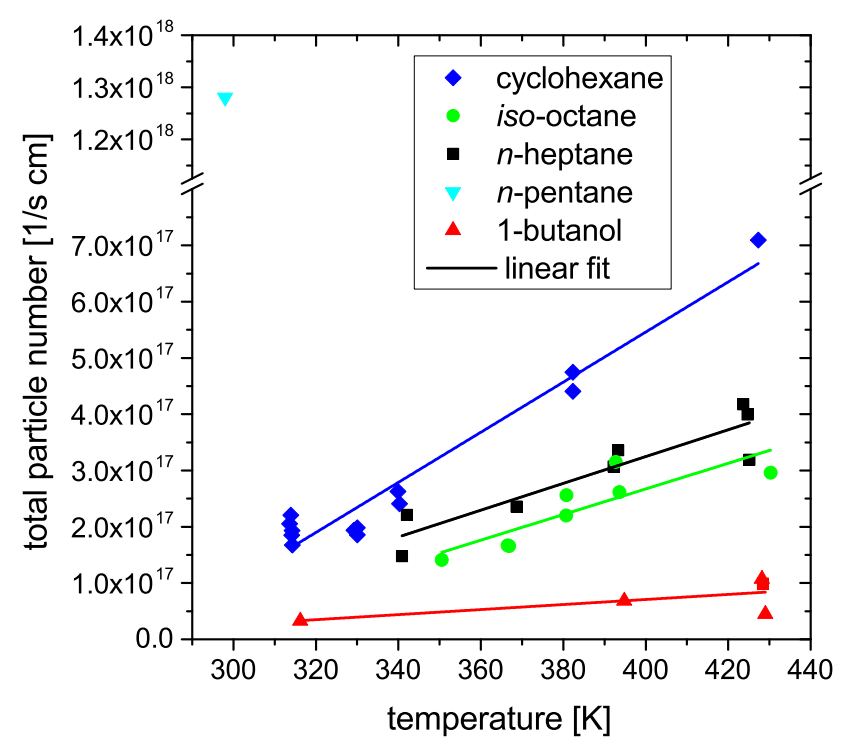

Fig. 10 Dependence of the evaporation rate (in particles per time and unit length) on temperature and comparison between different fuels.

tion rates of different chemical compounds at a droplet chain.

The laser absorption measurement technique has proven to be very powerful in combination with the droplet chain. The laser and detector were easy to handle and were commercially available at moderate costs. A very good spatial resolution was required for the measurement, as the vapor concentration decreased by typically $90 \%$ within the first millimeter of radial distance from the droplet chain. The HeNe laser had a good beam quality that made it possible to achieve a focus diameter, determined by a knife-edge method, of $30 \mu \mathrm{m}$ (FWHM) with a lens of $80 \mathrm{~mm}$ focal length. The spatial resolution can thus be regarded as completely sufficient. In the current setup, the detection limit for fuel vapor mole fractions was on the order of 0.001 which is regarded as sufficient for validations of numerical models. This was achieved with measurement duration of $1 \mathrm{~s}$.

The temperature of the coflow was measured by a thermocouple with a diameter of $250 \mu \mathrm{m}$. The corresponding spatial resolution is poor compared to that of the absorption measurement. However, for most of the conditions studied here, the spatial temperature changes were small. The maximum temperature change measured along $\mathrm{x}$ was only $30 \mathrm{~K}$ and thus spatial averaging effects with respect to temperature were of minor importance. For larger temperature gradients a better spatial resolution should be aimed at, e.g. by using a very thin thermocouple or an adequate optical technique.

The current absorption technique with IR HeNe laser can be used for the detection of a large number of hydrocarbon species. However, it becomes more difficult when multi-component hydrocarbon mixtures are considered because the contributions of the different constituents to the total absorption cannot be distinguished. Thus, further techniques must be used, and for two- or three-components mixtures solutions are possible. One option is to use an additional laser for an absorption measurement within a specific absorption band that exists only in one fuel component. With regard to spatial resolution, a good beam quality of the additional laser must be provided and not every laser type can meet this requirement. A promising approach is the combination of IR absorption with laser-induced fluorescence (LIF), provided one component is detectable by LIF. At least 
for aromatic hydrocarbons LIF presents an option. However, it should be kept in mind that for quantitative LIF concentration measurements effects induced by molecular collisions, such as fluorescence quenching, line broadening or vibrational and electronic energy transfer, can complicate the data evaluation. Since the corresponding molecule-specific quantities required for the data evaluation are only known for a few species, extensive calibration measurements may be necessary. In contrast, the laser absorption measurements are relatively simple and calibration free. Finally it is noted that absorption measurements can be readily combined with techniques for the determination of droplet size or composition.

Acknowledgements The work described in present paper was funded by the German Aerospace Center (DLR) in the frame of internal projects "R2F" and "Future Fuels". The authors would like to thank Patrick Nau for his valuable support in data analysis and in the lab. The authors also thank Uwe Riedel for useful discussions.

\section{References}

1. W. Sirignano. Fluid Dynamics and Transport of Droplets and Sprays. Cambridge University Press, (2010).

2. S. S. Sazhin, Modelling of fuel droplet heating and evaporation: Recent results and unsolved problems, Fuel 196, $69-101$ (2017).

3. A. P. Pinheiro and J. M. Vedovoto, Evaluation of droplet evaporation models and the incorporation of natural con- vection effects, Flow Turbul. Combust. 102, 537-558 (2019).

4. M. Birouk and I. Gökalp, Current status of droplet evaporation in turbulent flows, Prog. Energy Combust. Sci. 32, $408-423$ (2006).

5. A. Lefebvre and V. McDonnel. Atomization and Sprays. CRC Press, 2nd edition, (2017).

6. S. B. Saharin, B. Lefort, C. Morin, C. Chauveau, L. L. Moyne, and R. Kafafy, Vaporization characteristics of ethanol and 1-propanol droplets at high temperatures, Atomization and Sprays 22, 207-226 (2012).

7. P. Strizhak, R. Volkov, G. Castanet, F. Lemoine, O. Rybdylova, and S. Sazhin, Heating and evaporation of suspended water droplets: Experimental studies and modelling, Int. J. Heat Mass. Transf. 127, 92 - 106 (2018).

8. G. Xiao, K. H. Luo, X. Ma, and S. Shuai, A molecular dynamics study of fuel droplet evaporation in sub- and supercritical conditions, Proc. Combust. Inst. 37, 3219 3227 (2019)

9. S. Horender and M. Sommerfeld, Evaporation of nearly monosized droplets of hexane, heptane, decane and their mixtures in hot air and an air/steam mixture, Int. J. Spray Combust. Dyn. 4, 123-153 (2012).

10. P. Kulkarni, P. A. Baron, and K. Willeke. Aerosol measurement: principles, techniques, and applications. John Wiley \& Sons, (2011).

11. F. Lemoine and G. Castanet, Temperature and chemical composition of droplets by optical measurement techniques: a state-of-the-art review, Exp. Fluids 54, 1572 (2013).

12. C. Tropea, Optical particle characterization in flows, Annu. Rev. Fluid Mech. 43, 399-426 (2011). 
13. Y. Wu, C. Crua, H. Li, S. Saengkaew, L. Mädler, X. Wu, and G. Gréhan, Simultaneous measurement of monocomponent droplet temperature/refractive index, size and evaporation rate with phase rainbow refractometry, J. Quant. Spectrosc. Radiat. Transf. 214, 146 - 157 (2018).

14. J. Wilms and B. Weigand, Composition measurements of binary mixture droplets by rainbow refractometry, Appl. Opt. 46, 2109-2118 (2007).

15. C. D. Rosebrock, S. Shirinzadeh, M. Soeken, N. Riefler, T. Wriedt, R. Drechsler, and L. Mädler, Time-resolved detection of diffusion limited temperature gradients inside single isolated burning droplets using rainbow refractometry, Combust. Flame 168, 255 - 269 (2016).

16. G. S. Settles and M. J. Hargather, A review of recent developments in schlieren and shadowgraph techniques, Meas. Sci. Technol. 28, 042001 (2017).

17. H.-E. Albrecht, N. Damaschke, M. Borys, and C. Tropea. Laser Doppler and phase Doppler measurement techniques. Springer, (2003). Berlin, Heidelberg, New York.

18. Y. Zhao and H. H. Qiu, Measurements of multicomponent microdroplet evaporation by using rainbow refractometer and PDA, Exp. Fluids 40, 60 (2005).

19. T. D. Fansler and S. E. Parrish, Spray measurement technology: a review, Meas. Sci. Technol. 26, 012002 (2014).

20. T. Hillenbrand and D. Brüggemann. Substance related investigation of the evaporation characteristics of free falling alkane-ethanol droplets using Raman spectroscopy. In ILASS Europe. 29th european conference on Liquid Atomization and Spray Systems, (2019).

21. M. A. Linne. Spectroscopic Measurement: An Introduction to the Fundamentals. Academic Press, (2002). Am- sterdam.

22. D. A. Long. The Raman Effect: A Unified Treatment of the Theory of Raman Scattering by Molecules. John Wiley \& Sons, (2002).

23. C. Schulz and V. Sick, Tracer-LIF diagnostics: quantitative measurement of fuel concentration, temperature and fuel/air ratio in practical combustion systems, Prog. Energy Combust. Sci. 31, 75 - 121 (2005).

24. S. Bejaoui, X. Mercier, P. Desgroux, and E. Therssen, Laser induced fluorescence spectroscopy of aromatic species produced in atmospheric sooting flames using UV and visible excitation wavelengths, Combust. Flame 161, $2479-2491(2014)$

25. M. Orain, P. Baranger, C. Ledier, J. Apeloig, and F. Grisch, Fluorescence spectroscopy of kerosene vapour at high temperatures and pressures: potential for gas turbines measurements, Appl. Phys. B 116, 729-745 (2014).

26. M. C. Thurber, F. Grisch, B. J. Kirby, M. Votsmeier, and R. K. Hanson, Measurements and modeling of acetone laser-induced fluorescence with implications for temperature-imaging diagnostics, Appl. Opt. 37, 49634978 (1998).

27. O. Dégardin, B. Renou, and A. M. Boukhalfa, Simultaneous measurement of temperature and fuel mole fraction using acetone planar induced fluorescence and rayleigh scattering in stratified flames, Exp. Fluids 40, 452-463 (2006).

28. S. Sahu, Y. Hardalupas, and A. M. K. P. Taylor, Simultaneous droplet and vapour-phase measurements in an evaporative spray by combined ILIDS and PLIF techniques, Exp. Fluids 55, 1673 (2014). 
29. M. Stöhr, S. Werner, and W. Meier. Experimental study of liquid-vapor mass transfer in non-reacting and reacting droplet chains. In ILASS Europe. 28th european conference on Liquid Atomization and Spray Systems, 738-745. Editorial Universitat Politècnica de València, (2017).

30. C. Liu and L. Xu, Laser absorption spectroscopy for combustion diagnosis in reactive flows: A review, Appl. Spectrosc. Rev. 54, 1-44 (2019).

31. W. Cai and C. F. Kaminski, Tomographic absorption spectroscopy for the study of gas dynamics and reactive flows, Prog. Energy Combust. Sci. 59, 1 - 31 (2017).

32. R. K. Hanson, Applications of quantitative laser sensors to kinetics, propulsion and practical energy systems, Proc. Combust. Inst. 33, $1-40$ (2011).

33. F. K. Tittel, R. Lewicki, R. Lascola, and S. McWhorter. Emerging Infrared Laser Absorption Spectroscopic Techniques for Gas Analysis, chapter 4, 71-109. John Wiley \& Sons, Ltd (2013).

34. W. Mallard and W. Gardiner, Absorption of the 3.39 $\mu \mathrm{m}$ He-Ne laser line by methane from 300 to $2400 \mathrm{~K}, \mathrm{~J}$. Quant. Spectrosc. Radiat. Transf. 20, 135 - 149 (1978).

35. D. B. Olson, W. G. Mallard, and J. W. C. Gardiner, High temperature absorption of the $3.39 \mu \mathrm{m}$ He-Ne laser line by small hydrocarbons, Appl. Spectrosc. 32, 489-493 (1978).

36. M. Perrin and J. Hartmann, High temperature absorption of the $3.39 \mu \mathrm{m}$ He-Ne laser line by methane, J. Quant. Spectrosc. Radiat. Transf. 42, 459 - 464 (1989).

37. J. A. Drallmeier, Hydrocarbon absorption coefficients at the $3.39 \mu \mathrm{m}$ He-Ne laser transition, Appl. Opt. 42, 979 $982(2003)$.
38. S. J. Ruoff, B. Rauch, P. Le Clercq, and M. Aigner. Assessment of the Comparability of Droplet Evaporation Fuel Sensitivities between a Unit Test Case and an Aviation Gas Turbine Combustor. In AIAA Scitech 2019 Forum, 0727, (2019).

39. C. L. Yaws. Chapter 10 - Diffusion Coefficient in Air Organic Compounds. In Transport Properties of Chemicals and Hydrocarbons, C. L. Yaws, editor, $407-496$. William Andrew Publishing, Boston (2009).

40. National Institute of Standards and Technology. NIST Chemistry WebBook. http://webbook.nist.gov/.

41. W. Demtröder. Laser Spectroscopy 1. Springer, (2014). Berlin, Heidelberg.

42. C. S. Goldenstein, R. Spearrin, J. B. Jeffries, and R. K. Hanson, Infrared laser-absorption sensing for combustion gases, Prog. Energy Combust. Sci. 60, 132 - 176 (2017).

43. C. J. Dasch, One-dimensional tomography: a comparison of abel, onion-peeling, and filtered backprojection methods, Appl. Opt. 31, 1146-1152 (1992).

44. E. Tomita, N. Kawahara, M. Shigenaga, A. Nishiyama, and R. W. Dibble, In situ measurement of hydrocarbon fuel concentration near a spark plug in an engine cylinder using the $3.392 \mu \mathrm{m}$ infrared laser absorption method: discussion of applicability with a homogeneous methane-air mixture, Meas. Sci. Technol. 14, 1350-1356 (2003).

45. M. A. Alrefae. Mid-IR Absorption cross-section measurements oh hydrocarbons. Master's thesis, King Abdullah University of Science and Technology, (2013).

46. R. Mevel, P. Boettcher, and J. Shepherd, Absorption cross section at $3.39 \mu \mathrm{m}$ of alkanes, aromatics and substituted hydrocarbons, Chem. Phys. Lett. 531, $22-27$ (2012). 
47. A. E. Klingbeil, J. B. Jeffries, and R. K. Hanson, Temperature- and pressure-dependent absorption cross sections of gaseous hydrocarbons at $3.39 \mu \mathrm{m}$, Meas. Sci. Technol. 17, 1950-1957 (2006).

48. Dortmund Data Bank. DDBST GmbH. http://www.ddbst.com/, (Version 2015).

49. G. Castanet, L. Perrin, O. Caballina, and F. Lemoine, Evaporation of closely-spaced interacting droplets arranged in a single row, International Journal of Heat and Mass Transfer 93, $788-802$ (2016). 